\title{
Criação de um herbário virtual como recurso didático para o ensino de Botânica
}

\author{
Creation of a virtual herbarium as a didactic resource for teaching Botany \\ Creación una herbaria virtual como recurso didáctico para la enseñanza Botánica
}

Recebido: 12/01/2021 | Revisado: 18/01/2021 | Aceito: 22/01/2021 | Publicado: 28/01/2021

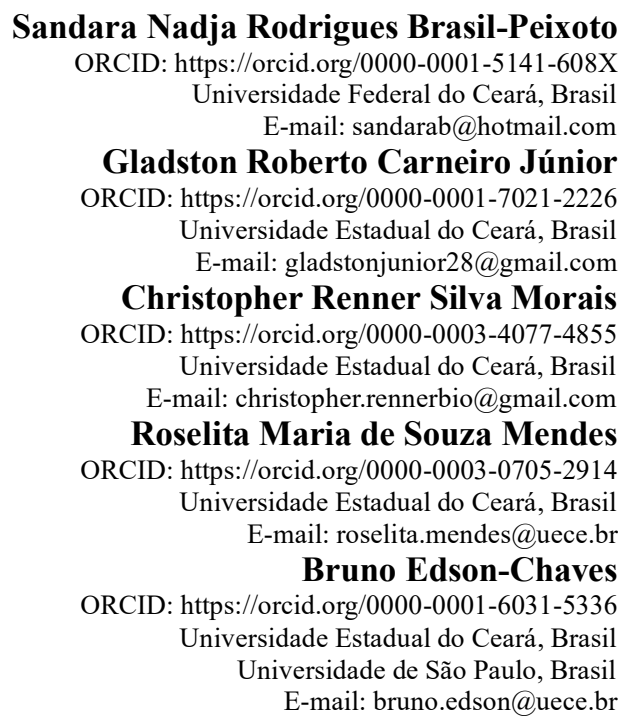

\begin{abstract}
Resumo
O modelo atual empregado no ensino de Ciências tem merecido críticas que apontam a necessidade de renovar as concepções de aprendizagem de professores e alunos; onde o aluno é uma parte fundamental no processo de ensino e aprendizagem. O uso de multimídias, jogos de computador e o acesso à Internet tornam-se artifícios fundamentais para atrair a atenção dos adolescentes. No ensino de Botânica o uso destes recursos apresenta-se como uma valiosa estratégia para desenvolver conceitos acerca da morfologia das plantas. O termo herbário virtual é utilizado para designar a disponibilização de imagens digitais de exsicatas herborizadas via Internet. Seu uso pode auxiliar nas aulas de Botânica no Ensino Médio, uma vez que os alunos têm a possibilidade de visualizar imagens de exsicatas com a comodidade da Internet. $\mathrm{O}$ trabalho buscou construir um site com imagens de espécies vegetais herborizadas (exsicatas) e imagens comparativas de plantas in vivo, que foram utilizadas nas aulas de Botânica do Ensino Médio. Foram incluídas no site imagens de plantas herborizadas e in vivo, registradas durante um levantamento florístico realizado em conjunto com alunos de uma escola da rede pública de Fortaleza, em seguida o herbário foi aplicado uma aula na referida escola. Além disso, o site foi avaliado por meio do SAM e SMOG, onde se obteve um resultado satisfatório em relação ao objetivo do trabalho.
\end{abstract}

Palavras-chave: Taxonomia; Exsicatas; Letramento científico.

\begin{abstract}
The current model used in science education has been criticized for pointing out the need to renew the learning concepts of teachers and students; where the student is a key part of the teaching and learning process. The use of multimedia, computer games and access to the Internet become fundamental devices to attract the attention of adolescents. In the teaching of Botany, the use of these resources presents itself as a valuable strategy to develop concepts about plant morphology. The term virtual herbarium is used to designate the availability of digital images of herborized exsiccates via the Internet. Its use can assist in botany classes in high school, since students have the possibility to view images of exsiccates with the convenience of the Internet. The work sought to build a website with images of herborized plant species (exsiccates) and comparative images of plants in vivo, which were used in high school botany classes. Images of herborized and in vivo plants were included on the website, recorded during a floristic survey carried out together with students from a public school in Fortaleza, after which the herbarium was applied to a class at that school. In addition, the site was evaluated using SAM and SMOG, where a satisfactory result was obtained in relation to the objective of the work.
\end{abstract}

Keywords: Taxonomy; Exsiccates; Scientific literacy. 


\section{Resumen}

El modelo actual utilizado en la educación científica ha sido criticado por señalar la necesidad de renovar los conceptos de aprendizaje de profesores y estudiantes; donde el alumno es una pieza clave del proceso de enseñanza y aprendizaje. El uso de multimedia, juegos de computadora y el acceso a Internet se convierten en dispositivos fundamentales para atraer la atención de los adolescentes. En la enseñanza de la botánica, el uso de estos recursos se presenta como una estrategia valiosa para desarrollar conceptos sobre la morfología de las plantas. El término herbario virtual se utiliza para designar la disponibilidad de imágenes digitales de excretas herborizadas a través de Internet. Su uso puede ayudar en las clases de botánica en la escuela secundaria, ya que los estudiantes tienen la posibilidad de ver imágenes de exsiccates con la comodidad de Internet. El trabajo buscó construir un sitio web con imágenes de especies de plantas herborizadas (exsiccates) e imágenes comparativas de plantas in vivo, que se utilizaron en las clases de botánica de la escuela secundaria. En el sitio web se incluyeron imágenes de plantas herborizadas e in vivo, registradas durante un relevamiento florístico realizado junto a estudiantes de una escuela pública de Fortaleza, luego de lo cual se aplicó el herbario a una clase de esa escuela. Además, se evaluó el sitio mediante SAM y SMOG, donde se obtuvo un resultado satisfactorio en relación al objetivo del trabajo.

Palabras clave: Taxonomía; Exsicca; Alfabetización científica.

\section{Introdução}

O modelo comumente empregado no ensino de Ciências não leva em conta a construção do conhecimento científico, bem como as exigências relativas aos valores humanos, à construção de uma visão da Ciência relacionada com a Tecnologia, a Sociedade e ao papel dos métodos das diferentes ciências. Desse modo, esse modelo tem recebido críticas que apontam a necessidade de renovar as concepções de aprendizagem de professores e alunos (Brasil, 1997).

Dentre os conteúdos de ciências merece destaque a Botânica, área que estuda as plantas, esta é subdividida em: Fisiologia Vegetal, Morfologia e Anatomia Vegetal, Sistemática e Taxonomia Vegetal (Costa, 2011), entre outras. Com isso, é importante a preservação e o estudo das espécies de plantas por atuarem, por exemplo, na arborização urbana que são utilizadas para a redução da temperatura e qualidade do ar das cidades sendo responsável por reduzir até $4^{\circ} \mathrm{C}$ de temperatura, além de melhorar a paisagem urbana (Silva \& Oliveira, 2020).

No Brasil, o ensino de Botânica ainda acontece predominantemente de forma expositiva e com a utilização do livro didático, sem que haja contato com os vegetais ou com práticas que envolvam os organismos estudados, gerando dificuldade e desmotivação por parte do aluno que atua apenas como ouvinte nessas aulas (Feiffer et al., 2018). Desta forma é fundamental que os professores desenvolvam atividades em que os alunos possam visualizar a Botânica no seu dia a dia, estimulando reflexões (Nunes et al., 2015), ampliando o seu olhar para a matéria, incentivando-o a estudar e aumentar seu interesse pelo conteúdo (Pereira \& Fernandes, 2018).

Uma estratégia que permite aproximar a Botânica dos estudantes é a utilização de herbários didáticos/escolares. O herbário designa a coleção de vegetais preparados, dissecados, classificados e catalogados, segundo o grupo a que pertencem e que se conservam nas instituições de Botânica para fins de ensino e pesquisa (Costa et al., 2019). Quando aplicados no contexto educacional demonstra-se um forte instrumento didático, pois permite o reconhecimento da flora de um determinado local ou região, saindo do âmbito de aulas conteudistas (Oliveira \& Freixo, 2019), ao mesmo tempo em que possibilitará ao professor uma exploração do conteúdo de forma mais aplicada e significativa para o aluno, bem como desempenha um papel importante no processo de aprendizagem e familiarização dos termos técnicos botânicos (Fagundes \& Gonzales, 2006).

Considerando que os meios digitais já fazem parte da rotina de muitos estudantes, o uso desta tecnologia pode tornarse uma importante ferramenta educacional para atrair a atenção dos alunos no processo de ensino e aprendizagem (Monteiro et al., 2016). Este recurso permite uma visualização menos abstrata do conteúdo, além de favorecer uma educação de qualidade por ir além das aulas teóricas, acarretando no aperfeiçoamento do ensino (Silva, Silva \& Coelho, 2016).

Com isso, a criação de um herbário virtual dinamiza e facilita o acesso às informações presentes em uma determinada coleção local. Além de disponibilizá-las na internet para os mais diversos públicos como acadêmicos, docentes e outros 
interessados (Bragança \& Leão, 2013). Quando imagens digitais das exsicatas (material herborizado) de uma coleção estão disponíveis em ambiente on-line, é comum denominá-las de herbário virtual.

No Brasil e no mundo, muitos herbários disponibilizam suas coleções de modo virtual. Estas coleções poderiam atuar promovendo uma educação além dos muros das instituições de modo a divulgar os dados botânicos na internet e auxiliar nas aulas de Botânica no Ensino Médio. Tal fato aproximaria os herbários virtuais das proposições de Amorim et. al. (2019) que é levar o conhecimento científico dos herbários para os espaços informais.

Seguindo estes preceitos, este trabalho visa descrever a criação de um herbário virtual didático e sua avaliação por meio de SAM e SMOG para observar a sua funcionalidade como ferramenta de ensino de Botânica para os alunos do Ensino Médio.

\section{Metodologia}

\subsection{Tipologia da pesquisa}

Esse trabalho apresenta natureza qualitativa, onde os métodos se configuram a procedimentos de interpretação dos fenômenos por parte do autor, sem buscar enumerar ou medir eventos, e, geralmente, não emprega instrumental estatístico para análise dos dados (Pereira et al., 2018). Além disso, a pesquisa tem caráter descritivo que objetiva compreender o fenômeno estudado, considerando os dados observados da realidade importantes para serem analisados. Onde, o ambiente e os indivíduos envolvidos são vistos como um todo, além do processo da atividade ser bastante relevante para a observação (Godoy, 1995).

\subsection{Escolha do material utilizado para a criação do herbário virtual}

O trabalho foi realizado em uma escola estadual do bairro João XXIII (Fortaleza, CE). No período do trabalho estava sendo desenvolvido na escola o projeto intitulado "Levantamento Florístico do Componente Arbustivo-Arbóreo do Bairro João XXIII" que tinha como objetivo realizar um levantamento dos espécimes do componente arbustivo-arbóreo do bairro com o intuito de fornecer suporte aos trabalhos de Educação Ambiental voltado à comunidade.

Para o levantamento foram realizadas caminhadas por todas as ruas contidas na área delimitada; cada uma das espécies inventariadas foi coletada (predominantemente em período reprodutivo) e herborizada seguindo procedimentos de Fidalgo e Bononi (1989); em seguida identificada por meio de literatura especializada e consulta a especialistas e depositadas em uma coleção didática para ensino de Biologia. Em campo também foram realizadas anotações das principais características do vegetal e registro fotográfico.

Com base nesse acervo e dada à carência de matérias motivadoras para as aulas de Biologia/Botânica, foi desenvolvido o herbário virtual com as plantas presentes a uma distância de 1-5 quarteirões da escola (esta variação ocorreu em virtude da posição da escola em relação às quatro vias principais do bairro). Ao final do trabalho, identificaram-se oito espécies arbóreas e arbustivas presentes nas áreas próximas da escola.

\subsection{Criação do site}

O herbário virtual foi implantado no Google sites, uma plataforma online e gratuita para criação de sites; para tanto o usuário que tem uma conta de e-mail e as páginas criadas não podem exceder 100 megabytes.

Para cada espécie, foram disponibilizadas no site duas imagens: (i) planta in loco; e (ii) amostras das exsicatas. Além disso, para cada uma das espécies selecionadas, é apresentado um texto que contém os seguintes aspectos: nome comum, nome científico, família, origem e descrição da morfologia externa (folhas, flores, frutos e sementes), bem como informações sobre a utilidade das espécies para o homem. As informações foram obtidas por meio de literatura especializada na área de botânica; todas as fontes consultadas encontram-se abaixo de cada planta citada. 
No site, os discentes ainda podem adicionar comentários, bem como realizar a atividade de curadoria, onde os próprios alunos terão a possibilidade de corrigir erros e sugerir modificações. Há ainda uma ferramenta de busca no próprio site, onde poderão ser buscados arquivos do próprio site ou no Google®.

Ainda na ferramenta on-line, foram adicionados links de acesso rápido a instituições que possuem um herbário digital, bem como a sites que exploram a temática, além de conter uma área de navegação que explica as técnicas utilizadas nos procedimentos de herborização.

\subsection{Avaliação do site}

Foi realizada uma análise da adequabilidade do site para o público alvo. O material foi aferido segundo a Suitability Assessment of Materials - SAM (Doak et al., 1996) e do Simple Measure of Gobbledygook - SMOG (McLaughlin 1969).

O SMOG analisa o nível de leiturabilidade do material analisado (Havard, 2014). O site apresenta seis tópicos que neles possuem as definições de herbário, espécies catalogadas, ferramentas necessárias para a fabricação das exsicatas, procedimentos em campo e laboratório. Dessa forma, foram retiradas 30 frases construídas nos tópicos iniciais, intermediários e finais para serem analisadas no parâmetro avaliativo SMOG; tais frases foram selecionadas aleatoriamente pelo site https://sorteador.com.br/.

O SAM avalia com um questionário fatores como a adequação cultural, o layout e tipografia, estimulação ao aprendizado, a objetividade do conteúdo, leiturabilidade e gráficos (Doak et al., 1996). Para avaliar os fatores, foi caracterizada nota 0 como "Não adequado", 1 para "Adequado" e 2 para "Excelente". Alguns fatores não se aplicam para a avaliação do Herbário Virtual.

\section{Resultados e Discussão}

\subsection{Espécies catalogadas}

No levantamento, foram encontradas oito espécies (duas nativas e seis exóticas), distribuídas em sete famílias (Tabela 1). Essas famílias e a maioria dessas espécies são comuns em alguns bairros de Fortaleza, como demonstra Moro e Westerkamp (2011). Assim, o trabalho contribui para a importância de conhecer e identificar a flora do local urbanizado, o que auxilia para a manutenção do ecossistema local através da arborização urbana (Silva \& Oliveira, 2020). Desta forma, é imprescindível que os alunos conheçam a importância da relação do tipo de vegetação, nativa e exótica, nas cidades que pode influenciar negativamente ou não no ecossistema.

A diferença entre o número absoluto das espécies nativas e exóticas demonstra uma valorização das exóticas na paisagem. Essa substituição promove uma uniformização das vegetações urbanas e danos causados pelas espécies exóticas às espécies nativas, por ser potenciais invasoras (Lesse et al., 2020).

A espécie mais representativa foi a Ficus benjamina L. (41 indivíduos) que, segundo Braga (1960), possui incrível rapidez de crescimento, abundância e beleza da folhagem. As características citadas fizeram desta Moraceae a planta preferida para a arborização em diversas cidades brasileiras, apesar de seu sistema radicular ser prejudicial à conservação dos passeios. 
Tabela 1: Espécies encontradas durante o levantamento florístico. Legenda: №. Número Absoluto; N\%. Número percentual (valores apresentados estão em percentual).

\begin{tabular}{llllll}
\hline \multicolumn{1}{c}{ Família } & \multicolumn{1}{c}{ Nome científico } & Nome Comum & $\mathbf{N}^{\mathbf{0}}$ & N\% & Origem \\
\hline Moraceae & Ficus benjamina L. & Ficus & 41 & 34,7 & Exótica \\
Meliaceae & Azadirachta indica A. Juss. & Nim & 37 & 31,3 & Exótica \\
Myrtaceae & Syzygium malaccense (L.) Merr. \& & Jambeiro & 15 & 12,7 & Exótica \\
& LMPerry & & & & \\
Malvaceae & Pachira aquatica Aubl. & Munguba & 12 & 10,1 & Nativa \\
Fabaceae & Cassia siamea Lam. & Cassia & 7 & 5,9 & Exótica \\
Anacardiaceae & Anacardium occidentale L. & Cajueiro & 3 & 2,5 & Nativa \\
Anacardiaceae & Mangifera indica L. & Mangueira & 2 & 1,6 & Exótica \\
Combretaceae & Teminalia catappa L. & Castanholeira & 1 & 0,8 & Exótica \\
\hline
\end{tabular}

Fonte: Autores.

A segunda espécie mais encontrada foi o Nim (Azadirachta indica A. Juss.), apresentando 37 espécimes. O Nim foi trazido da Índia e tem se tornado bastante popular por suas características medicinais e repelentes. Além de ser uma das plantas que mais se repete no cenário vivenciado pelos alunos, a espécie tem inúmeras utilidades para o homem. Na agricultura, pode ser utilizado para o controle de insetos-praga, apresenta ação nematicida e atua sobre fungos e bactérias. Ainda pode ser usado na fabricação de cosméticos, reflorestamento e na arborização urbana, como madeira de lei, além de fertilizante (Embrapa, 2008). Contudo, esta espécie apresenta um alto potencial de disseminação tornando-a uma praga invasora (Moro, Westerkamp \& Martins, 2013).

Além das espécies supracitadas, é imprescindível que os alunos conheçam a importância da preservação da vegetação nativa. Neste sentido, o Cemig (2001) cita que é importante conhecer e identificar a flora nativa do Brasil, pois contribuem para a manutenção do ecossistema local e global através da preservação da fauna e flora nativas de cada região.

Dentre as espécies nativas observadas no levantamento encontra-se Pachira aquatica Aubl. (Munguba) e Anacardium occidentale L. (Cajueiro) - Tabela 1. A primeira apresenta-se como árvore que produz uma ótima sombra, muito utilizada na arborização urbana (Lorenzi, 2008). Apresentou potencial de interesse nos alunos pela folhagem brilhante, pela flor de coloração e forma exótica e pelo seu fruto que é semelhante ao cacau, sendo, por isso, também conhecida pela denominação de cacaufalso. A segunda tem relevante utilidade para o homem, como: antiinflamatório em caprinos e ovinos em regiões do Nordeste (Sousa et al., 2020) e na produção de bebidas nutritivas à base de extrato de castanha de caju, conforme Firmo, Sousa e Cavalcanti (2020). Com essas características e potenciais de uso, é imprescindível a preservação desses tipos de plantas nativas. O caju possui também um potencial larvicida contra o Aedes aegypti (Guissoni et al., 2013).

\subsection{O Herbário Virtual}

A proposta de criação do site foi articulada a partir da percepção da carência de projetos inovadores para as aulas de Botânica no Ensino Médio. As pesquisas educacionais e as discussões entre especialistas apontam a utilização de outros recursos didáticos, por exemplo, a informática, como materiais com os quais os professores poderiam buscar a superação dos modelos clássicos do ensino de Ciências (Teixeira, 2006). 
Assim, a proposta de utilização desta ferramenta foi centrada no Ensino Médio, que, segundo os Parâmetros Curriculares Nacionais (PCN), revela-se um nível em que o aprendizado deve-se realizar pela participação ativa de cada um, professores e alunos, e do coletivo educacional numa prática de elaboração cultural (Brasil, 2000). O currículo do Ensino Médio permite uma abordagem maior do ensino de Botânica.

Nesse contexto, o levantamento florístico, importante para a criação do site o Herbário Virtual, teve como participação dos alunos e do professor como auxiliador. O que torna uma metodologia ativa que, segundo Leite e Ramos (2017), o aluno participa ativamente diante de uma situação-problema, fazendo com que ocorra uma reflexão por parte dele, e o professor atua como mediador no processo de ensino.

Além disso, para que o aprendizado seja significativo é preciso que esteja integrado no contexto pessoal do aluno. As mídias fazem parte do contexto contemporâneo e do cotidiano dos alunos, pois estão inseridas na vida social das pessoas. Então, o professor pode integrar e ensinar ao aprendiz a interpretar as informações vistas por meio da tecnologia ou até utilizar dessa ferramenta para a educação (Leite \& Almeida, 2017).

O herbário virtual produzido (Figura 1) encontra-se hospedado no seguinte endereço eletrônico: https://sites.google.com/site/virtualherbario. O nome Herbário Virtual reporta-se à identidade do site, que contém imagens de plantas herborizadas remetendo a um herbário: coleção científica de amostras de plantas prensadas, dissecadas e identificadas referentes a uma determinada região.

Existem outros sites com o nome parecido e que passam a identidade de um herbário com uma quantidade de registros, dentre estes se destacam o Flora do Brasil 2020, criado a partir de integrantes do Jardim Botânico do Rio de Janeiro em dezembro de 2010 (http://floradobrasil.jbrj.gov.br/). Outro exemplo seria o INCT - Herbário Virtual da Flora e dos Fungos que se encontra no endereço eletrônico: http://inct.splink.org.br.

O herbário virtual produzido proporciona aos professores e estudantes outro modo de ensino e aprendizagem. Esse tipo de ferramenta didática atua como motivação pelo estudo para os alunos, uma ferramenta prática que armazena diversas informações com fácil acesso. Além de contribuir em diversas áreas da Biologia e Botânica pode atuar também ao nível de graduação (Maciel, 2017).

A interface do site elaborado mostra-se clara e de fácil acesso (Figura 1). O que é muito relevante nos ambientes virtuais de ensino para que possa ocorrer uma boa usabilidade.

Segundo Bassani et al. (2010) os usuários devem ser capazes de perceber a informação, operar a interface, compreender as informações apresentadas e terem acesso a conteúdo confiável. As atividades das pessoas durante a interação e a percepção dos recursos e ferramentas nos sistemas devem ser facilitadas pela interface do ambiente virtual para uma melhor experiência (Lima, Merino \& Triska, 2018). Assim, o usuário fica mais a vontade de fazer as consultas de conteúdos botânicos no site do Herbário Virtual por ser confiável e facilmente utilizável pelo público. 
Figura 1: Visão geral da interface do site com os tópicos divididos a esquerda (Herbário Virtual, Espécies, Links Importantes, Técnicas de Herborização) e os conteúdos apresentados na parte central.

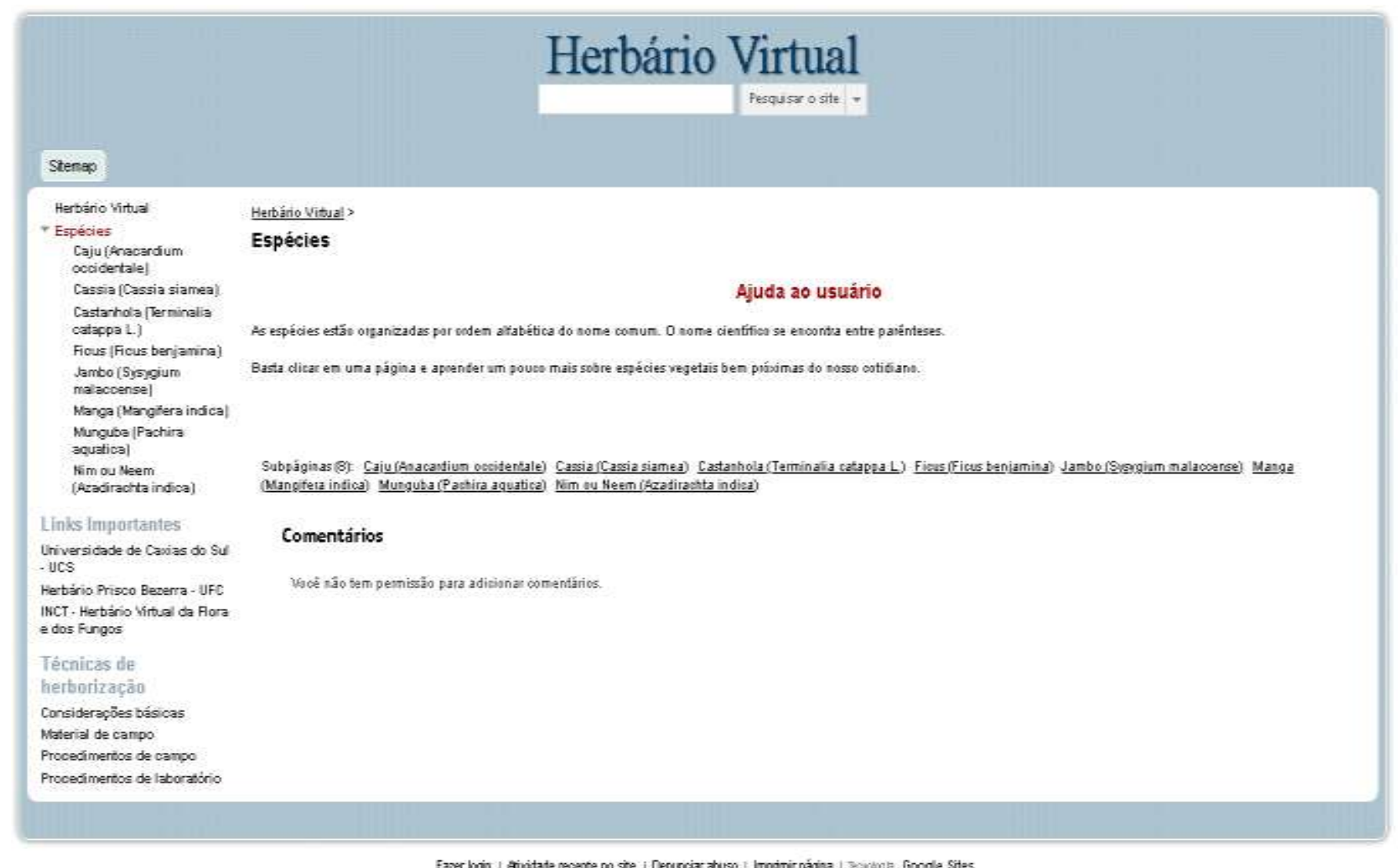

Fonte: https://sites.google.com/site/virtualherbario

As páginas de conteúdo seguem um padrão, a partir do qual torna mais fácil a acessibilidade do site. O mesmo foi elaborado de modo que a linguagem utilizada se aproxime do público-alvo, e apresenta listas que realçam palavras-chave do conteúdo. Para Miranda et al. (2017) o material deve apresentar-se com uma linguagem compreensiva e acessível para não dificultar o entendimento do público alvo e ter uma leitura fluida.

\subsection{Aba espécies}

O site disponibiliza as espécies de forma que o aluno observa os grupos de gênero e família dos vegetais. A indicação das famílias botânicas facilita a compreensão do aluno, permitindo-o generalizar as características dos indivíduos estudados dentro de um determinado grupo (Moran, Masseto \& Behrens, 2000). Na aba de cada espécie é apresentada, no mínimo, duas imagens (uma herborizada e outra(s) em seu ambiente natural), sendo possível observar a floração, os aspectos morfológicos de suas folhas e sua disposição (Figura 2). 
Figura 2: Página do site referente à espécie Pachira aquatica Aubl.

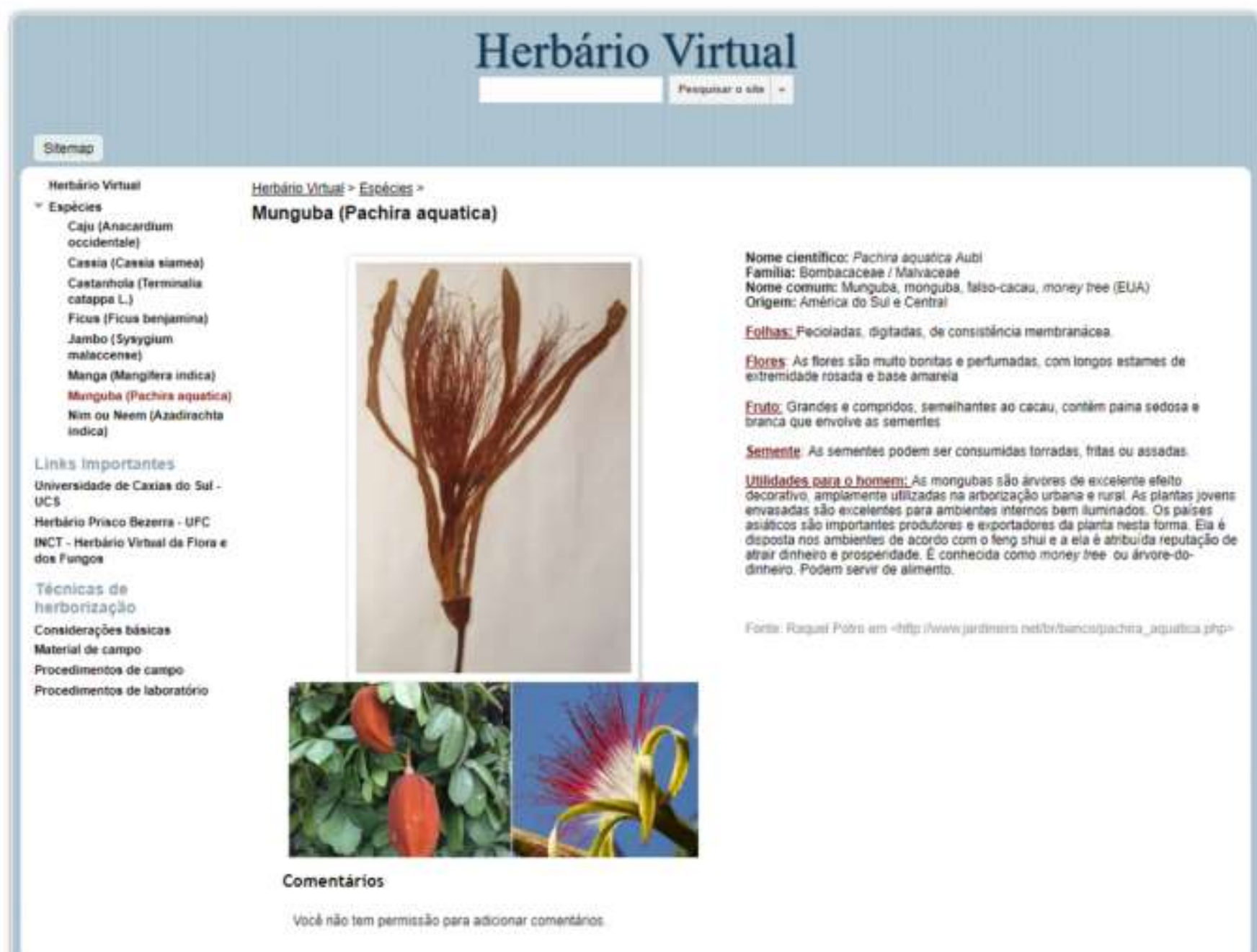

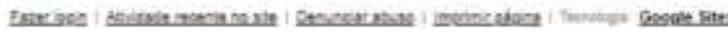

Fonte: https://sites.google.com/site/virtualherbario/herbario-virtual/home/munguba-pachira-aquatica.

Os aspectos textuais explorados (nome comum, nome científico, família, origem e descrição da morfologia externa) têm papel relevante no ambiente escolar; auxiliando na formação do aluno como cidadão autônomo (Lima et al., 2019), além de organizar as informações de forma adequada. Os tópicos e a distinção de cada informação deixam a busca das informações mais dinâmica e prática sendo um atrativo para os jovens que por fazerem muita busca devido a gama de informações presentes na internet (Barboza, Edson-Chaves \& Lucena, 2020).

Além disso, nos textos de cada espécie demonstram-se a relevância e a utilidade da espécie para o homem. Cada texto com sua fonte específica da pesquisa, mostrando a importância da divulgação científica para a sociedade em sala de aula. Segundo Brasil (2018), é necessário o comprometimento da educação básica com o letramento científico do aluno para a sua formação, para sua contribuição na sociedade e no mundo, sendo capaz de não somente de transformá-lo, mas também desenvolvê-lo.

\subsection{Abas referentes aos links importantes e técnicas de herborização}

Na barra de navegação horizontal à esquerda denominada Links Importantes (Figura 1) estão os sites da Universidade de Caxias do Sul, Herbário Prisco Bezerra, e do Herbário Virtual da Flora e Fungos do Brasil. Tendo sido dado ênfase a sites 
que tenham conteúdos relevantes ao Herbário Virtual. Esses tipos de ferramentas proporcionam uma autonomia para o aluno utilizar para estudos, sendo ele o protagonista do seu aprendizado no momento da busca. Além disso, ocorre que esses tipos de ferramentas virtuais estão atrelados ao cotidiano do aluno, o que motiva ainda mais a sua busca (Costa, Duarte \& Gama, 2019).

O site contém páginas referentes às técnicas de herborização, onde estão contidas informações sobre materiais de campo, procedimentos de campo e informações básicas, retirados do Manual de Prática de Coleta e Herborização de Material Botânico (Embrapa, 2008). É importante que o aluno entenda como as plantas foram herborizadas, observando a biodiversidade vegetal e conhecendo as abrangentes características das espécies vegetais. Entender a importância de um herbário como fonte de pesquisa para todas as áreas da ciência que fazem uso dos vegetais, além de compreender todo o processo de incorporação de uma exsicata a um herbário, seja ele físico ou virtual.

Além disso, o herbário virtual proporciona uma ferramenta de fácil acesso à informação o que torna o mecanismo de busca no site "Herbário Virtual" ainda mais interessante que permite a pesquisa por palavras-chave ou conteúdo do aluno ou professor com o uso do site (Maciel, 2017).

A pesquisa pode ser feita tanto no site Herbário Virtual como no buscador Google®. As operações de busca e localização de páginas no site seguem um padrão devido à importância dos usuários saberem que o mesmo comando ou uma mesma ação terá sempre o mesmo efeito, o que os deixariam mais confiantes no uso do software, sentindo-se mais encorajados a fazer novas buscas e ter novas descobertas (Winckler \& Pimenta, 2008).

\subsection{Apreciações do site Herbário Virtual segundo os Parâmetros Curriculares Nacionais para o Ensino Médio}

A construção do Herbário Virtual teve como principal norteador os Parâmetros Curriculares Nacionais para o Ensino Médio (PCNEM). Este trabalho encaixa-se em dois temas estruturadores da Biologia: Interação entre os seres vivos e Diversidade da vida.

A pesquisa também envolve uma relação entre temas como tecnologia, ciência, sociedade e ambiente, inserindo e mostrando ao aluno as relações socioambientais com as tecnologias a disposição. A BNCC (Base Nacional Comum Curricular) sugere uma contextualização social e cultural da ciência e tecnologia, fundamentando essa relação como iniciativa humana e formação cultural. Ademais, propõe que os alunos sejam capazes de entender a ponto de intervir no ambiente em que vivem (Brasil, 2018).

Em relação a biodiversidade, é importante para o aluno conhecer as independências dos organismos e interpretar as relações entre a atividade humana e a biodiversidade para que possa ocorrer um cuidado com o ambiente (Dagostin-Gomes et al., 2017). O conhecimento adquirido pelos alunos com o uso do Herbário Virtual envolveu não somente aspectos taxonômicos (conhecimento das famílias e aspectos morfológicos de cada espécie), mas também ecológicos (relação de plantas nativas e exóticas e questões adaptativa das espécies) e ambientais que atua no contexto da arborização urbana para uma melhor qualidade de vida.

No tópico "Espécies", é mostrada a importância de cada planta para o homem, capacitando o discente a ponderar sobre a valia de cada planta para a sociedade. $\mathrm{O}$ que está relacionado aos serviços ambientais e aos saberes associados à biodiversidade que devem ser trabalhados em sala de aula (Brasil, 2006).

Desse modo, segundo Silva e Bezerra (2016), a abordagem da Educação Ambiental é muito importante para atingir uma sustentabilidade e faz-se necessário para o processo contínuo com base na qualidade de vida e consciência ambiental individual, preservando espécies nativas e ambientes verdes. A presente pesquisa é capaz de mostrar que tipos de espécies estão sendo disseminadas ou cultivadas no ambiente e nas cidades em que vivemos, pois destaca as origens das espécies e a sua ocorrência no local estudado, além das suas características. 


\subsection{Análise do Herbário virtual por meio do SMOG}

O SMOG faz uma estimativa da quantidade de anos de estudo necessários para a compreensão do material didático analisado, avaliando o nível de leiturabilidade. O cálculo envolve a contabilização de palavras com 3 ou mais sílabas (McLaughlin, 1969). Contudo, nesse trabalho, o método foi adaptado, contabilizando somente palavras polissílabas. Segundo Vidal-Amaral (2016) o SMOG foi criado a partir da língua inglesa que possui palavras mais curtas do que o português, sendo esta adaptação necessária para análise de textos em português.

Após a análise das frases, obteve-se o resultado de 55 palavras polissílabas (Tabelas 2 e 3). Conforme o cálculo do SMOG obteve o valor 10; tal valor corresponde ao número de anos de estudo que uma pessoa deve ter para entender o material. Segundo Martins e Filgueiras (2007), representa um nível de escolaridade de conclusão do $9^{\circ}$ ano do Ensino Fundamental até o $2^{\circ}$ ano do Ensino Médio. Com isso, pode-se afirmar que a criação do site e utilização dele em sala de aula a nível Fundamental e Médio é cabível para aprendizagem do público-alvo.

Tabela 2: Frases analisadas nos Tópicos iniciais do site Herbário Virtual (01-10 frases). A contagem efetuada pelo SMOG referese ao número de palavras com 4 ou mais sílabas, estas palavras estão destacadas em itálico nas frases selecionadas. Abreviaturas: $\mathrm{N}^{\circ}$, Número da frase sorteada; Cont., Contagem.

\begin{tabular}{clc}
\hline $\mathbf{N}^{\mathbf{0}}$ & Frase selecionada & Cont. \\
\hline 3 & Um herbário é uma coleção de amostras botânicas prensadas, secas e identificadas. & 2 \\
9 & O que são técnicas de herborização? & 2 \\
11 & Para isso é preciso utilizar boas práticas de coleta e identificação. & 1 \\
14 & Folhas: Forma oval, glabras (sem pelos) e coriáceas (textura de couro) & 1 \\
17 & Fruto: A castanha é o fruto verdadeiro. \\
21 & O cajueiro é uma árvore originária do Brasil, nativo da região litorânea. \\
27 & A casca do caju é usada no tratamento de afta e infecções na garganta. \\
32 & Semente: são achatadas, oblongo-ovaladas, contidas no interior do legume. \\
36 & Folhas: Ovais e de textura coriácea (aspecto de couro). \\
40 & Semente: dura, cônica, levemente achatada e alongada. & 3 \\
\hline Subtotal 1 (somatória das palavras polissílabas das frases 01-10) & 1 \\
\hline
\end{tabular}

Fonte: Autores. 
Tabela 3: Frases analisadas nos Tópicos iniciais do site Herbário Virtual (11-30 frases). A contagem efetuada pelo SMOG referese ao número de palavras com 4 ou mais sílabas, estas palavras estão destacadas em itálico nas frases selecionadas. Abreviaturas: $\mathrm{N}^{\mathrm{o}}$, Número da frase sorteada; Cont., Contagem.

\begin{tabular}{|c|c|c|}
\hline $\mathbf{N}^{\mathbf{0}}$ & Frase selecionada & Cont. \\
\hline 42 & A madeira é de boa qualidade, dura, avermelhada e resistente à água. & 3 \\
\hline 47 & O uso medicinal popular aproveita, além das folhas, os frutos, raízes, casca e sementes. & 2 \\
\hline 51 & Flores: Discretas e brancas não têm valor ornamental. & 1 \\
\hline 60 & $\begin{array}{l}\text { Semente: grande, globosa, de } 1,6-2 \mathrm{~cm} \text { de diâmetro, de textura carnosa, castanho-clara no exterior e verde no } \\
\text { interior. }\end{array}$ & 3 \\
\hline 61 & Utilidades para o homem: Possui uma madeira vermelha, pesada, dura, difícil de se trabalhar e fácil de empenar. & 1 \\
\hline 63 & O fruto é consumido ao natural, sendo recomendado para compor saladas. & 2 \\
\hline 69 & Flores: Pequenas, de cor amarelo-esverdeada, reunidas em cachos que surgem das extremidades dos ramos. & 2 \\
\hline 73 & O fruto é consumido "in natura", processado em doces, geléias, sucos e molhos (como o mango chutney). & 2 \\
\hline 75 & As folhas podem ser consumidas cozidas. & 1 \\
\hline 79 & Flores: As flores são muito bonitas e perfumadas, com longos estames de extremidade rosada e base amarela. & 3 \\
\hline 47 & O uso medicinal popular aproveita, além das folhas, os frutos, raízes, casca e sementes. & 2 \\
\hline 85 & $\begin{array}{l}\text { Ela é disposta nos ambientes de acordo com o feng shui e a ela é atribuída reputação de atrair dinheiro e } \\
\text { prosperidade. }\end{array}$ & 4 \\
\hline 89 & Flores: numerosas e pequenas. & 1 \\
\hline 93 & Usada para arborização de ruas e praças, usada no campo como quebra-vento e como sombra. & 2 \\
\hline 95 & Pode ser usado como repelente natural. & 1 \\
\hline 102 & Etiqueta de papel em branco (para as anotações). & 2 \\
\hline 104 & Se possível máquina fotográfica. & 1 \\
\hline 106 & Evitar coletar material muito úmido, para prevenir o ataque de fungos. & 1 \\
\hline 115 & Isso facilita a observação do material que, depois de seco, corre o risco de quebrar (folha) ou cair do ramo. & 3 \\
\hline 119 & As prensas de madeira são encaminhadas às estufas de secagem. & 1 \\
\hline \multicolumn{2}{|r|}{ Subtotal 2 (somatória das palavras polissílabas das frases 11-30) } & 38 \\
\hline \multicolumn{2}{|c|}{ TOTAL (30 frases selecionadas) } & 55 \\
\hline \multicolumn{2}{|c|}{ Raiz quadrada do valor total + 3 (Mc Laughlin, 1979) } & 10 \\
\hline
\end{tabular}

Fonte: Autores.

A análise feita pelo método alternativo de SMOG do texto de Barboza, Edson-Chaves e Lucena (2020) teve como resultado semelhante ao do Herbário Virtual apresentado neste trabalho, mostrando que ambos os recursos on-line apresentam acessibilidade do texto para pessoas com 10 anos de estudo. Ou seja, acessível ao público de educação básica, podendo ser usado por professores em sala nas suas aulas práticas ou para consultas de um público mais abrangente. 
A análise geral por meio SAM (Tabela 4) indica que o site Herbário Virtual obteve 29 escores (76,32\% dos escores possíveis), de modo que o material pode ser considerado excelente para o aprendizado, podendo ser utilizado como uma ferramenta de consulta ou até utilizá-la como fonte de conteúdo em sala de aula. A pontuação do Herbário Virtual teve uma pontuação parecida com a do trabalho de Almeida et al. (2016), que classifica seu material como excelente para uso didático com 30 escores.

Tabela 4: Escores dos fatores aferidos pela análise do SAM que se aplica: 0 (não se aplica), 1 (adequado) ou 2 (excelente). Após todos os critérios terem sido avaliados, somam-se os pontos e compara-se com a tabela existente em Doak et al. (1996) para verificar o nível do material produzido.

\begin{tabular}{|c|c|c|}
\hline Parâmetros & Critérios & Pontuação \\
\hline \multirow[t]{4}{*}{ Conteúdo } & Objetivo evidente & 2 - Excelente \\
\hline & Os conteúdos sobre comportamento & 2 - Excelente \\
\hline & Resumo ou revisão incluída & Não se aplica \\
\hline & Competência limitada & 2 - Excelente \\
\hline Demanda de & Nível de leitura & 2 - Excelente \\
\hline \multirow[t]{4}{*}{ alfabetização } & Estilo de escrita & 2 - Excelente \\
\hline & Contexto & 1 - Adequado \\
\hline & Vocabulário & 1 - Adequado \\
\hline & Marcadores auxiliadores de aprendizagem & 2 - Excelente \\
\hline \multirow[t]{5}{*}{ Gráficos } & Capa & 1 - Adequado \\
\hline & Tipos de ilustrações & 2 - Excelente \\
\hline & Relevância das ilustrações & 1 - Adequado \\
\hline & Listas, tabelas, gráficos entre outros & Não se aplica \\
\hline & Legendas & 0 - Não adequado \\
\hline Layout e & Tipografia & 2 - Excelente \\
\hline \multirow[t]{2}{*}{ tipografia } & Layout & 2 - Excelente \\
\hline & Utilização de Subtítulos & 2 - Excelente \\
\hline Estímulo ao & Interações & 1 - Adequado \\
\hline \multirow[t]{2}{*}{ aprendizado } & Padrões de comportamento desejados & Não se aplica \\
\hline & Motivação & 2 - Excelente \\
\hline \multirow[t]{2}{*}{ Adequação cultural } & Correspondência cultural & 2 - Excelente \\
\hline & Imagens culturais & 0 - Não adequado \\
\hline
\end{tabular}

Fonte: Autores.

Além disso, O Herbário Virtual obteve uma maior pontuação com relação ao material analisado no trabalho de Barboza, Edson-Chaves e Lucena (2020) e o classificou como um excelente material auxiliador para o processo de ensino-aprendizagem. 
Dos parâmetros analisados merecem destaque: (i) Conteúdo, (ii) Demanda de alfabetização, (iii) Layout e tipografia e (iv) Estímulo ao aprendizado que possuem $75 \%$ ou mais da pontuação dos critérios analisados consideradas excelentes.

O parâmetro de Conteúdo do Herbário Virtual teve nota máxima, mostrando que ele atingiu o objetivo descrito na primeira aba do site (Herbário Virtual). Além disso, os alunos ajudaram na pesquisa e registro das espécies dispostas no site, resultando nota máxima no critério "conteúdo sobre comportamento". O site objetivou identificar as plantas, mostrando suas características morfológicas e utilidades para a sociedade, representando um aspecto importante para o letramento científico de quem faz uso do site. Dessa forma, o Herbário Virtual teve como resultado mais adequado do que o material de Almeida et al. (2016) e semelhante ao de Silva (2020) que enfatiza a importância da objetividade de conteúdo.

Ademais, o parâmetro de Demanda de alfabetização desse trabalho apresentou 90\% da nota máxima, além do nível de leitura atingir excelência na nota, como mostrado pelo SMOG (Tabelas 2 e 3) o texto apresenta o Estilo de escrita direto e compreensível e Marcadores auxiliadores de aprendizagem que dinamizam as informações apresentadas. Além disso, o aluno observa de perto a pesquisa na produção de um herbário, ocorrendo uma contextualização sobre a matéria. O que representa mais adequado que o trabalho de Almeida et al. (2016). Observa-se que o critério de Vocabulário é qualificado como adequado, apesar de uma boa leiturabilidade, o texto ainda apresenta nomenclaturas específicas do vocabulário científico, como a indicação de nomes científicos. Esse critério assemelha-se a pesquisa de Miranda et al. (2017) que atinge a mesma pontuação.

No quesito de Layout e tipografia, o site é representado com a nota máxima devido a distinção eficiente dos conteúdos apresentados. Dessa forma, o Herbário Virtual apresenta, de forma conveniente, os conteúdos sem que o usuário se sinta confuso. A avaliação equivale ao trabalho de Barbosa, Edson-chaves e Lucena (2020) que atingiu 86\% da nota e ao trabalho de Miranda et al. (2017) com excelência nesse quesito na avaliação do SAM.

No parâmetro de Estímulo ao aprendizado, observa-se que não atinge a nota máxima, pois o Herbário Virtual apresenta apenas uma interação com o discente que é a produção e pesquisa do conteúdo pelos alunos no levantamento florístico das áreas próximas da escola, mas no texto/site não ocorrem interações como resoluções de problemas ou questionamentos para o leitor. Esta característica é observada no trabalho de Miranda et al. (2017), onde na produção do material não havia interação presente no texto. Nesse quesito, a interação com leitor, envolvendo algumas questões sobre o assunto, pode estimular a habilidade intelectual do leitor com o material em questão. Ademais, o Herbário Virtual atinge uma excelência no critério de Motivação por disponibilizar informação de forma rápida e dinâmica em um ambiente acessível, resultando em uma motivação para usuários fazerem pesquisas e realizarem mais consultas.

A análise dos Gráficos do Herbário Virtual representou 50\% da nota total deste critério, pois o site não proporcionou: (i) legendas para as ilustrações divulgadas e (ii) ilustrações na aba de "Técnicas de herborização", demonstrando as ferramentas envolvidas. Quanto ao primeiro ponto, a presença e legendas ajudam a uma melhor identificação das ilustrações, sendo assim importante para o usuário; quanto ao segundo a ausência de certas ilustrações podem dificultar a identificação de certas ferramentas mencionadas. Nos trabalhos de Miranda et al. (2017) e Silva (2020), cujos materiais didáticos foram elaborados de forma bem ilustrativa, além da presença de legendas para melhor compreensão do leitor. A presença de ilustrações é importante para a melhor identificação do público com relação às espécies envolvidas, uma vez que os leitores estão familiarizados com elas (SILVA, 2020); o Herbário Virtual ilustra bem somente as espécies registradas e as descreve ao nível de espécie, características morfológicas, uso na sociedade entre outros.

Por fim, na análise de Adequação cultural atinge nota Excelente no critério de Correspondência cultural por ser um texto sem gírias ou palavras regionalizadas. Assemelhando-se ao trabalho de Miranda et al. (2017) que observa essa característica no texto como culturalmente adequado, sendo acessível a todos os leitores. Ademais, o site falha no critério de Imagens culturais, resultando em não adequado, pois seria possível ilustrar imagens do uso das espécies mencionadas na sociedade, buscando um conceito menos abstrato para o usuário. 


\section{Considerações Finais}

O uso de novas tecnologias como websites, pode tornar o assunto interessante. Além do fato de essa metodologia ser mais atraente, é também conveniente para o aluno, pois a sua formação deve ter como alvo principal além da obtenção de conhecimentos básicos; a preparação científica e a habilidade de utilizar as diferentes tecnologias disponíveis em seu ambiente.

As espécies encontradas durante o levantamento florístico podem ser, em sua maioria, encontradas nos demais logradouros da cidade de Fortaleza. Tal fato favorece a utilização do site como ferramenta de ensino, pois seu conteúdo poderá extravasar os muros da escola e vir a ser aplicado em várias outras instituições de ensino.

O trabalho é muito relevante para os alunos observarem as plantas ao redor da escola, pois o herbário virtual partiu do estudo realizado pelos próprios com espécies próximas à escola, identificando-as, pesquisando características delas, observando e registrando às partes importantes para a criação do herbário virtual. Com isso observa-se que o trabalho faz uso de metodologia ativa, onde o aluno participa de forma não tradicional das aulas refletindo e buscando a resolução de situações-problema e o professor atua como mediador da situação.

O site do Herbário Virtual demonstrou ser uma ferramenta que auxilia na educação ambiental e na botânica com o acesso facilitado pela internet permitindo aos usuários uma familiarização dos termos e conceitos de botânica do ensino médio. Além de permitir uma aproximação da pesquisa científica com os alunos da educação básica.

Além disso, o trabalho pode inspirar outras atividades em sala de aula como a criação do herbário da própria turma, inserindo a pesquisa científica na educação dos alunos. Essa ferramenta pode ser utilizada por professores e alunos, além de servir de exemplo para posteriores produções de sites semelhantes em outras escolas. Assim, os docentes poderiam investigar esses métodos em sala de aula e produzir pesquisas científicas como esta.

\section{Referências}

Almeida, F. B. B., Mendes, R. M. S., Lucena, E. M. P., \& Edson-Chaves, B. (2016). Manual teórico-prático de Criptógamas como recurso auxiliar nas aulas práticas no ensino superior. Revista Brasileira de Biociências, 14(4), 243-249.

Amorim, G. S., Pires, C. S., Santos, C. R., Nascimento, A. D., Bielenki Junior, E. B. A., \& Valle, M. G. (2019). Herbários como espaços facilitadores para o processo de ensino e aprendizagem. Revista Trópica-Ciências Agrárias e Biológicas, 11(1), 36-45.

Barboza, R. M., Edson-Chaves, B., \& Lucena, E. M. P. (2020). Glossário online de botânica como recurso didático para o ensino médio. In: Lemos, J. R. Ciências biológicas: campo promissor para pesquisas, v. 4: Atena, p.127-140.

Bassani, P. B. S., Behar, P. A., Heidrich, R. O., Bittencourt, A., \& Ortiz, E. S. (2010). Usabilidade e acessibilidade no desenvolvimento de interfaces para ambientes de educação à distância. Revista Novas Tecnologias na Educação, 8, 1-10.

Braga, R. (1960). Plantas do Nordeste, especialmente do Ceará. (2 ${ }^{\mathrm{a}}$ ed.): Fundação Vingt-un Rosado.

Bragança, C. S., \& Leão, F. F. (2013). Confecção de coleção botânica para o herbário virtual da UFT - Campus de Gurupi. In: Seminário de Iniciação Científica da Universidade Federal de Tocantins, 9., 2013, Palmas. Anais... Palmas: UFT.

Companhia Energética de Minas Gerais (CEMIG). (2011). Manual de arborização: Fundação Biodiversitas.

Costa, E. A., Duarte, R. A. F., \& Gama, J. A. S. (2019). A gamificação da botânica: uma estratégia para a cura da "cegueira botânica". Revista Insignare Scientia, 2(4), 79-99.

Costa, L. B. S., Arouche, M. M. B., Moreira, J. F., \& Almeida Júnior, E. B. (2019). O herbário do Maranhão (MAR) que esperamos para o futuro: perspectivas e metas para garantir o registro da flora do Maranhão. Revista Trópica-Ciências Agrárias e Biológicas, 11(1), 46-55.

Costa, M. V. (2011). Material instrucional para ensino de botânica: CD-ROM possibilitador da aprendizagem significativa no ensino médio. Dissertação (Mestrado em Ensino de Ciências) - Universidade Federal de Mato Grosso do Sul, Campo Grande.

Dagostin-Gomes, I., Giassi, L., Mattos, A. S., Alves, A. V., Niehues, R. C., \& Formigoni de Luca, A. (2017). Extensão universitária e biodiversidade: promovendo educação ambiental nas Encostas da Serra Geral - sul de Santa Catarina. Revista ELO - Diálogos em Extensão, 6(2).

Doak, C., Doak, L., \& Root, J. (1996). Teaching patients with low literacy skills. (2 ${ }^{\mathrm{a}}$ ed.): Lippincot. 
Embrapa. (2008). Ministério da Agricultura, Pecuária e Abastecimento. Manual de prática de coleta e herborização de material botânico: Embrapa Florestas.

Fagundes, J. A., \& Gonzalez, C. E. F. (2006). Herbário escolar: suas contribuições ao estudo da Botânica no Ensino Médio: http://www.diaadiaeducacao.pr.gov.br/ portals/pde/arquivos/1675-8.pdf.

Feiffer, A. H. S., Miotto, H. S., Gonçalves, R. C., Benites, L. B., \& Dinardi, A. J. (2018). Aprendizagem de botânica a partir do levantamento de plantas herbáceas do Parque Estadual do Espinilho. In: Salão Internacional de Ensino, Pesquisa e Extensão, 10., 2018, Santana do Livramento. Anais: Universidade Federal do Pampa.

Fidalgo, O., \& Bononi, V. R. L. (1989). Técnicas de coleta, preservação e herborização de material botânico: Instituto de Botânica.

Firmo, A. Q., Sousa, M. M., \& Cavalcanti, M. S. (2020). Desenvolvimento e caracterização de bebidas produzidas à base de castanha de caju (Anacardium occidentale L.) Research, Society and Development, 9(1).

Godoy, A. S. (1995). Introdução à pesquisa qualitativa e suas possibilidades. Revista de Administração de Empresas, 35(2), 57-63.

Guissoni, A. C. P., Silva, I. G., Geris, R., Cunha, L. C., \& Silva, H. H. G. (2013). Atividade larvicida de Anacardium occidentale como alternativa ao controle de Aedes aegypti e sua toxicidade em Rattus norvegicus. Revista Brasileira de Plantas Medicinais, 15(3), $363-367$.

Harvard. (2014). Assessing and developing health materials. http://www.hsph.harvard.edu/healthliteracy/ practice/innovative-actions/.

Leite, L. S., \& Ramos, M. B. (2017). A metodologia ativa no ambiente virtual de aprendizagem. In: Silva, A. R. L., Bieging, P., \& Bussarello, R. I. (Org,). Metodologia ativa na educação: Pimenta Cultural. , p. 85-101.

Leite, M., \& Almeida, A. C. P. (2017). Processos criativos a partir da arte da fotografia. Trama Interdisciplinar, 8(2), $176-193$.

Lesse, E., Lucini, F., Kuster, M. C. T., Silva, F. A. B., Pereira, A. B., \& Laindorf, L. B. (2020). Incidência de erva-de-passarinho em espécies arbóreas da praça Tunuca Silveira, São Gabriel - RS. In: Salão Internacional de Ensino, Pesquisa e Extensão, 10, 2020, Santana do Livramento. Anais: Universidade Federal do Pampa.

Lima, G. F. A., Merino, E. A. D., \& Triska, R. (2018). Métodos mais usados para avaliações de Ambientes Virtuais de Aprendizagem (AVAs). Revista HFD Human Factors in Design, 7(13), 132-147.

Lima, R. A., Pinto, M. N., Mendoza, A. Y. G., Silva, D. R., Nascimento, F. A., Rodrigues, J. J. P., Almeida, K. P.C., Vieira, R. L., \& Assis, S. N. S. (2019). A importância das plantas medicinais para a construção do conhecimento em botânica em uma escola pública no município de Benjamin Constant-Amazonas (Brasil). Revista Ensino de Ciências e Humanidades-Cidadania, Diversidade e Bem Estar-RECH, 5, 478-492.

Lourenzi, H. (2008). Árvores brasileiras: manual de identificação e cultivo de plantas arbóreas nativas do Brasil. 1. (5ª ed.): Instituto Plantarum.

Maciel, L. M. (2017). Herbário virtual de fitopatologia: uma ferramenta importante para os discentes de Agronomia da Unilab. Trabalho de Conclusão de Curso (Graduação em Agronomia), Instituto de Desenvolvimento Rural, Universidade da Integração Internacional da Lusofonia Afro-brasileira, Redenção, Ceará.

Martins, S. J. O., \& Filgueiras, L. V. L. (2007). Métodos de avaliação de apreensibilidade das interfaces textuais: uma aplicação em sítios de governo eletrônico. In: Workshop on perspectives, challenges and opportunities for human-computer interaction in Latin American, 1., 2007. Anais.: SBC.

McLaughlin, G. H. (1969). SMOG grading: a new readability formula. Journal of Reading, 12(8), 639-649.

Ministério da Educação. Secretaria da Educação Fundamental. Parâmetros Curriculares Nacionais: Ciências Naturais. Brasília: MEC/SEF.

Ministério da Educação. Secretaria de Educação Básica. Base Nacional Comum Curricular: http://basenacionalcomum.mec.gov.br/.

Ministério da Educação. Secretaria de Educação Básica. Orientações Curriculares para o Ensino Médio: MEC/SEB.

Ministério da Educação. Secretaria de Educação Básica. Parâmetros Curriculares Nacionais: MEC/SEB.

Miranda, R. R., Mendes, R. M. S., Bonilla, O. H., Pantoja, L. D. M., \& Edson-Chaves, B. (2017). Desvendando a vegetação do Parque Botânico Estadual do Ceará através de uma cartilha educativa. Revista Brasileira de Biociências, 15(2), 28-34.

Monteiro, D. N., Ribeiro, T.C., Rocha, M. M. S., \& Athayde, F. R. (2016). Educação empreendedora: a influência da internet nos hábitos de leitura do adolescente. Revista de Educação a Distância, 3(2).

Moran, J. M.; Masseto, M. T. \& Behrens, M. A. (2000). Novas tecnologias e mediação pedagógica. (19a ed): Papirus.

Moro, M. F., \& Westerkamp, C.(2011). The alien street trees of Fortaleza (NE Brazil): qualitative observations and the inventory of two districts. Ciência Florestal, 21(4), 789-798.

Moro, M. F., Westerkamp, C., \& Martins, F. R. (2013). Naturalization and potential impact of the exotic tree Azadirachta indica A. Juss. in Northeastern Brazil. Check List 9 (1), 153-156.

Nunes, M. J. M., Oliveira, T. F., Souza, R. T. B., \& Lemos, J. R. (2015). Herbário didático como ferramenta diferenciada para a aprendizagem em uma escola de ensino médio em Parnaíba, Piauí. Momento, 24(2), 41-55.

Oliveira, J. F. C., \& Freixo, A. A. (2019). Contribuições de um herbário escolar para o ensino de ciências no contexto da educação do campo. Revista Eletrônica da FAINOR, 12(2), 386-403. 
Research, Society and Development, v. 10, n. 1, e52210111920, 2021

(CC BY 4.0) | ISSN 2525-3409 | DOI: http://dx.doi.org/10.33448/rsd-v10i1.11920

Pereira, A. S., Shitsuka, D. M., Parreira, F. J., \& Shitsuka, R. (2018). Metodologia da pesquisa científica. [e-book]. Santa Maria: UAB/NTE/UFSM. https://repositorio.ufsm.br/bitstream/handle/1/15824/Lic_Computacao_Metodologia-PesquisaCientifica. pdf?sequence=1.

Pereira, T. S., \& Fernandes, S. D. C. (2018). Material didático online sobre classificação vegetal para escolas sem acesso às áreas verdes. Revista Eixo, 7(2).

Silva, A. S., Garcia, A. F. G., Ribeiro, S. F. C., \& Jesús, S. F. (2017). Metodologias ativas: um desafio para o trabalho da orientação educacional. In: Silva, A. R. L., Bieging, P., \& Busarello, R. I. Metodologia ativa na educação: Pimenta Cultural.

Silva, H. O., \& Bezerra, R. D. (2016). A importância da educação ambiental no âmbito escolar. Revista Interface, 12, 163-172.

Silva, J. O. R., \& Oliveira, M. S. (2020). Arborização urbana e a educação ambiental como fatos conscientizador. Scientia Generalis, 1(2), 1-10.

Silva, K. C. M. A. P., Silva, T. C., \& Coelho, M. A. P. (2016). O uso da tecnologia da informação e comunicação na educação básica. In: Encontro Virtual de Documentação em Software Livre, 13.; Congresso Internacional de Linguagem e Tecnologia Online, 10. Anais... Evidosol, Ciltec on line, 5(1).

Silva, R. R. (2020). Manual de plantas medicinais como ferramenta de ensino-aprendizagem do conhecimento etnobotânico. Trabalho de Conclusão de Curso (Graduação em Licenciatura em Ciências Biológicas) - Universidade Estadual do Ceará, Fortaleza.

Sousa, V. F. O., Bandeira, A. S., Ribeiro, M. D. S., Santos, J. J. F., Santos, G. L., Silva, R. A., Maracajá, P. B., \& Costa, J. E. (2020). Uso de fitoterápicos na cura de enfermidades em animais no semiárido Paraibano. Research, Society and Development, 9(7), 1-15.

Teixeira, P. M. M. (Org.). (2006). Ensino de ciências: pesquisas e reflexões: Holos.

Vidal-Amaral, M. (2016). Leiturabilidade de cartilhas ambientais editadas pelo IBAMA - CE. Trabalho de Conclusão de Curso (Graduação em Ciências Biológicas), Centro de Ciências da Saúde - Universidade Estadual do Ceará, Fortaleza.

Winckler, M., \& Pimenta, M. S. (2008). Avaliação de usabilidade de sites web: Instituto de Informática - UFRGS, p. 85-137. 